\title{
Role of trans-cerebellar diameter in estimating gestational age in second and third trimester of pregnancy
}

\author{
Prashant Arun Uikey, Kshama Vivek Kedar, Surekha Narayan Khandale*
}

Department of Obstetrics and Gynaecology, Indira Gandhi Govt. Medical College, Nagpur, Maharashtra, India

\author{
Received: 30 June 2016 \\ Revised: 06 September 2016 \\ Accepted: 10 September 2016 \\ *Correspondence: \\ Dr. Surekha Narayan Khandale, \\ E-mail: drsurekha.narayankhandale@gmail.com
}

Copyright: ( ) the author(s), publisher and licensee Medip Academy. This is an open-access article distributed under the terms of the Creative Commons Attribution Non-Commercial License, which permits unrestricted non-commercial use, distribution, and reproduction in any medium, provided the original work is properly cited.

\begin{abstract}
Background: Uncertain gestational age is associated with higher perinatal mortality rates and an increased incidence of low birth weight and spontaneous preterm delivery. Errors in gestational age estimation can lead to iatrogenic neonatal morbidity from prematurity. Precise determination of gestational age antenatally is a boon to modern obstetrics in context with improved neonatal survival. The most effective way to date pregnancy is by sonography. Several parameters can be considered for estimation of gestational age trans-cerebellar diameter is one such parameter. The objective of this study was to study the role of fetal trans-cerebellar diameter in estimating the gestational age in second and third trimester of pregnancy and its correlation with gestational age, BPD, HC, AC and FL. The design of this study was to hospital based prospective cohort study conducted at department of obstetrics of Government medical College Nagpur, over a period of 1 year.

Methods: 500 women with sure dates between 7 and 11 weeks of gestation were booked. First trimester USG using crown rump length for confirmation of gestational age was done. These patients were advised to come for follow up till 40 weeks of gestation and repeat USG was done in second and third trimester. Trans-cerebellar diameter was correlated with expected gestational age with CRL, BPD, HC, AC and FL in weeks.

Results: $98.56 \%$ of variability in gestational age could be explained by variation in trans-cerebellar diameter (TCD) only. Addition of other variables did not make any significant difference indicating that TCD alone is the strong predictor of gestational age.

Conclusions: Normative cerebellar measurements throughout pregnancy permit estimation of gestational age independent of the shape of fetal head and also offer potential for evaluating abnormal fetal growth and anomalous development of central nervous system.
\end{abstract}

Keywords: Gestational, TCD, Pregnancy

\section{INTRODUCTION}

In today's era of small family, everyone would like to have a full grown healthy and normal baby. Sometimes due to hectic schedule or irregular cycles exact LMP is not known to the woman who leads to uncertainty. As we all aware that uncertain gestational age is associated with higher perinatal mortality rates and an increased incidence of low birth weight and spontaneous preterm delivery. Errors in gestational age estimation can lead to iatrogenic neonatal morbidity from prematurity. Determination of gestational age is important in obstetrics as uncertain gestational age is associated with higher perinatal morbidity and mortality rates and an increased incidence of low birth weight and spontaneous preterm delivery. Reliance on last menstrual period as sole determinant of gestational age is fraught with potential error from faulty memory or irregular cycle. 
Uterine size and quickening may be useful but not reliable. Precise determination of gestational age antenataly is a boon to modern obstetrics in context with improved neonatal survival. The most effective way to date pregnancy is by sonography. ${ }^{1}$ Several parameters can be considered for estimation of gestational age such as crown rump length (CRL), bi parietal diameter ( BPD), head circumference (HC), femur length (FL) and abdominal circumference (AC). In case of doubt, parameters used are, length of humerus, binocular distance and trans-cerebellar diameter (TCD). Studies have shown that in third trimester BPD becomes more related to growth than to gestational age. But it is unreliable in cases where shape of skull is distorted and hence the need for another parameter was felt and therefore we have endeavoured to determine the role of fetal trans-cerebellar diameter in estimating gestational age in second and third trimester of normal pregnancy by ultrasonography. ${ }^{2}$

The objective of this study was to study the role of fetal trans-cerebellar diameter in estimating the gestational age in second and third trimester of normal pregnancy, and to find out the correlation between TCD and gestational age, BPD, HC, AC and FL.

\section{METHODS}

It is a hospital based prospective cohort (correlative) study, conducted at Government medical College Nagpur over the period of one year. After getting approval from clinical epidemology unit. 500 consecutive women with sure of their dates between 7 and 11 weeks of gestation were booked.

\section{Inclusion criteria}

Women with optimal menstrual history i.e.

- She should be sure of first day of last menstrual period

- She should have got at least three normal menstrual cycles in length and duration of flow after the last child birth /abortion/evacuation

- She should not have taken oral contraceptive pills for at least two months before her last menstrual period

- She should not have an unusual bleeding since her last menstrual period.

\section{Single as well as multiple gestations (any presentation)}

Early bimanual examination for uterine size before 12 weeks agreed with menstrual dating

\section{Exclusion criteria}

- Women who are not sure of last menstrual period

- Women whose gestational age estimation was not done before 12 weeks by ultrasonography using CRL
- Women who are showing discrepancy of more than +- 7 days between menstrual age and that estimated by ultrasonography using CRL

- Impaired fetal growth or malformation existed

- Patient had any obstetric or medical complication of pregnancy.

All ultrasonic examinations were performed on real time ultrasound machine with linear array transducer having frequency of $3.5 \mathrm{mHz}$. First trimester USG using crown rump length for confirmation of gestational age was done. These patients were advised to come for follow up till 40 weeks of gestation and repeat USG was done in second or third trimester only once.

\section{Following parameters were studied}

- $\quad$ CRL

- $\mathrm{BPD}$

- $\mathrm{HC}$

- $\mathrm{AC}$

- FL

- $\mathrm{TCD}$

Out of 500 patients, 113 whose ultrasonography was done in first trimester did not come for follow up. 387 patients came for repeat USG in second and third trimester of pregnancy. At the time of their second ultrasound examination, thorough general and systemic examination was done to rule out any growth impairment and to detect any medical or obstetric complication of pregnancy. Clinical examination if reveals growth impairment or Glucose tolerance test is abnormal then such patients were excluded from study. 86 women out of 387 had complications like PIH (54), IUGR (20), GDM (7) and APH (5) hence they were excluded and analysis of 301 women was done. Averages of 3 readings of each parameter were taken to minimize the error.

\section{The analysis of data were done as follows}

- $\quad$ TCD in mm was correlated with expected gestational age by CRL in weeks

- $\quad \mathrm{TCD}$ in mm was correlated with expected gestational age by BPD in weeks

- $\quad \mathrm{TCD}$ in mm was correlated with expected gestational age by $\mathrm{HC}$ in weeks

- $\quad$ TCD in mm was correlated with expected gestational age by $\mathrm{AC}$ in weeks

- $\quad$ TCD in mm was correlated with expected gestational age by FL in weeks.

\section{RESULTS}

The gestational age was confirmed in first trimester and subsequently followed in second and third trimester, there was a strong correlation of GA and TCD $(r=0.972)$. The correlation of TCD with BPD was $(r=0.960)$, with HC $(r$ $=0.979)$, with $\mathrm{AC}(\mathrm{r}=0.980)$ and with FL $(\mathrm{r}=0.976)$ 
$98.56 \%$ of variability in gestational age could be explained by variation in TCD only. Addition of other variables did not make any significant difference indicating that TCD alone is the strong predictor of gestational age.

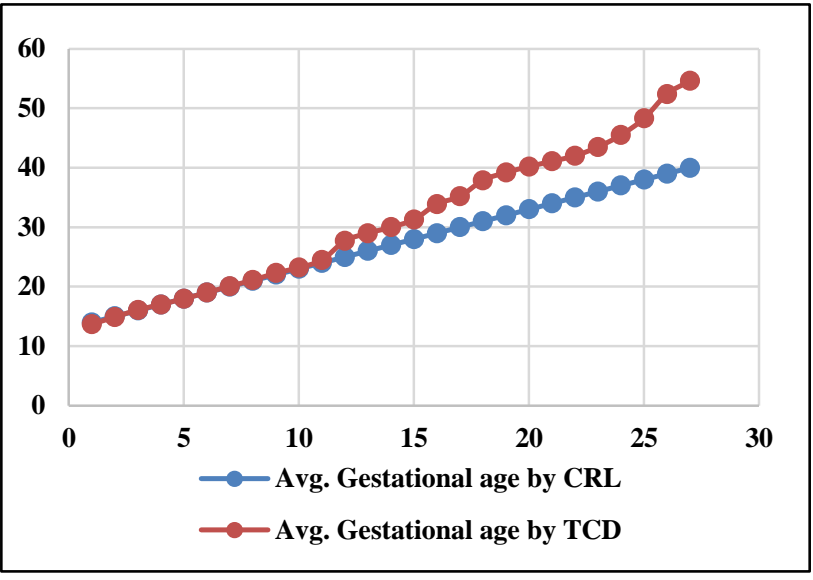

Figure 1: average gestational age expected by CRL in weeks and average TCD in $\mathrm{mm}$.

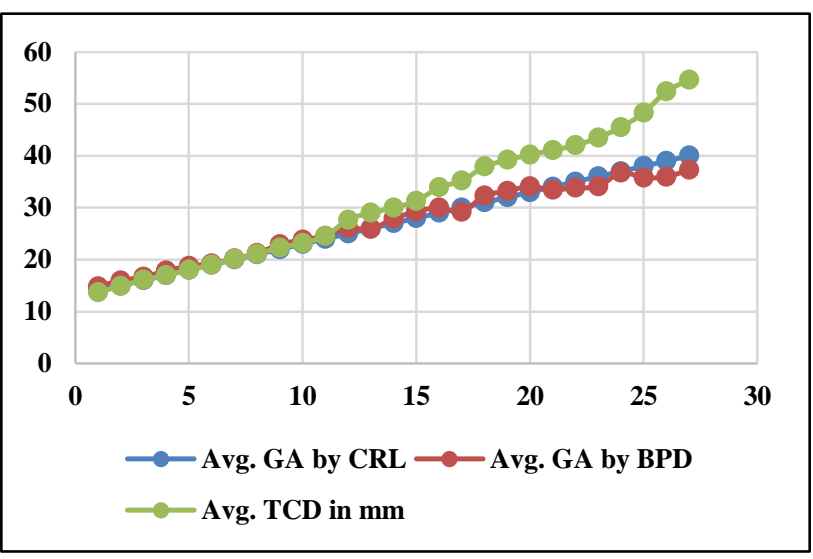

Figure 2: TCD in mm correlated with expected gestational age by BPD in weeks.

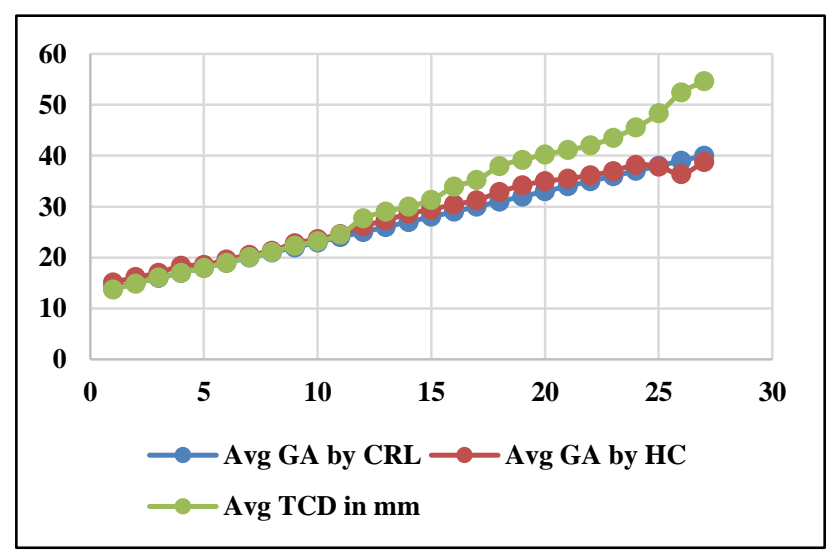

Figure 3: TCD in mm was correlated with expected gestational age by $\mathrm{HC}$ in weeks.

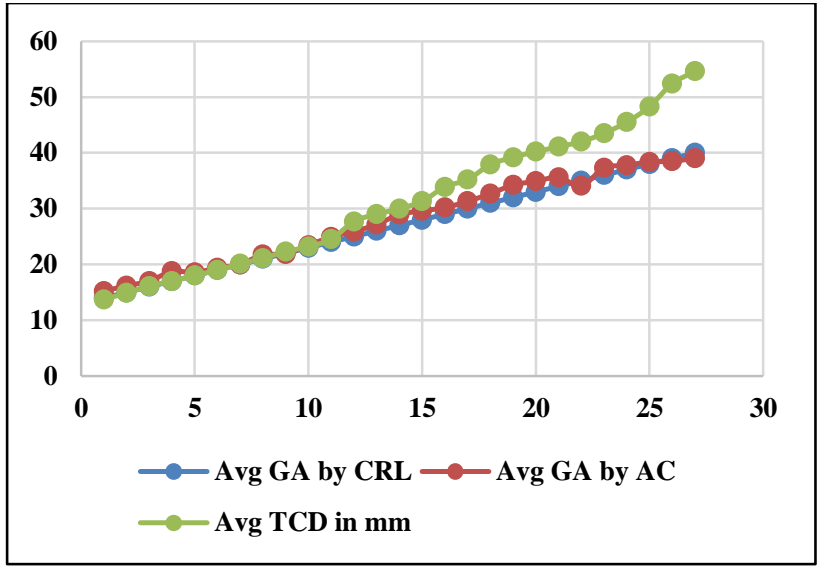

Figure 4: TCD in mm was correlated with expected gestational age by $\mathrm{AC}$ in weeks.

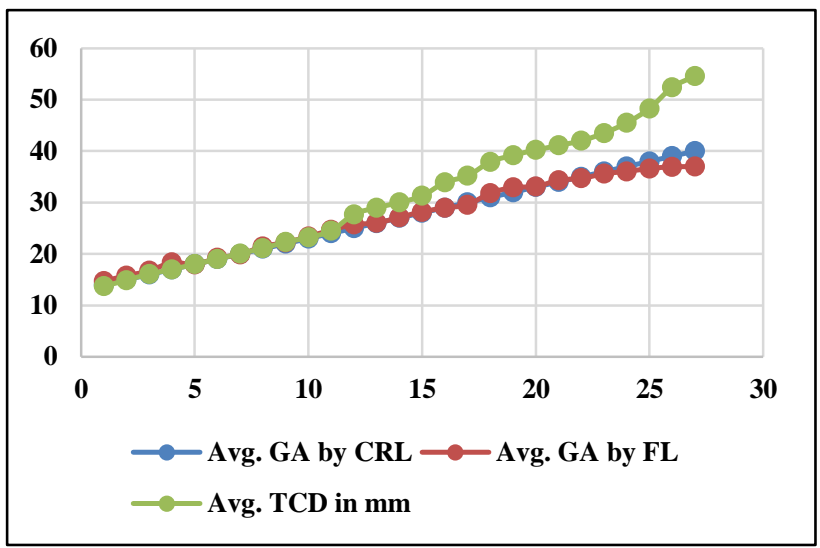

Figure 5: TCD in mm was correlated with expected gestational age by FL in weeks.

\section{DISCUSSION}

The knowledge of precise gestational age is very essential for the management of obstetric patients. Often there are situations where women presents herself for the first time in the third trimester of pregnancy with vague knowledge of pregnancy duration and many a times no idea about her last menstrual period. The clinician in such a situation is in dilemma and feels the need for some simple reliable means to estimate correct gestational age. In third trimester, no single parameter is reliable in estimating accurate gestational age as each of them got a discrepancy of more than 3 weeks. TCD is a parameter which has got no deformation in shape because of extrinsic pressure, which is not very much affected even in case of severe IUGR, can be used to date pregnancy reliably.

In present study 301 pregnant women were evaluated. The gestational age was confirmed by first trimester sonography and then prospectively followed either in second and/or third trimester and we found strong correlation of GA and TCD $(r=0.972)$. The correlation of TCD with BPD was $(r=0.960)$, with HC $(r=0.979)$, 
with $\mathrm{AC}(\mathrm{r}=0.980)$ and with $\mathrm{FL}(\mathrm{r}=0.976)$. The Goldstein et al studied 371 women from 13 to 40 weeks with several biometric parameters like TCD, BPD and occipito frontal diameter found curvilinear relationship between TCD and gestational age $(\mathrm{R} 2=0.948 ; \mathrm{p}=$ $0.0001)$, between TCD and BPD $(\mathrm{R} 2=0.956 ; \mathrm{p}=$ $0.0001)$, and between TCD and HC $(\mathrm{R} 2=0.969 ; \mathrm{p}=$ $0.0001) .^{3}$ TCD correlated strongly with gestational age. Mickovic $\mathrm{Z}$ et al studied 203 physiological pregnancies between 20 and 40 weeks of menstrual gestational age found strong correlation between TCD/MGA (R2 = $0.904)$ with $\mathrm{BPD} / \mathrm{TCD}(\mathrm{R} 2=0.914)$ and with $\mathrm{HC} / \mathrm{TCD}$ $(\mathrm{R} 2=0.919) .{ }^{4}$ Montenogro et al in 1989 studied 178 women between 17 to 24 weeks found that TCD is easy to obtain even in occipito- posterior positions and is independent of head shape and inter individual and constitutional discrepancies and is good marker for gestational age compared to other clinical parameters. ${ }^{5}$ While $\mathrm{H}$ et al in 1989 studied 116 women between 17 to 40 weeks of gestational age and TCD ( $\mathrm{r}=0.96 ; \mathrm{P}<$ $0.001) .^{6}$ They concluded that TCD is more useful indicator of the accurate gestational age in case of dolichocephaly or brachycephaly facilitate antenatal detection of congenital disorders. Nikolov $\mathrm{V}$ et al in their study of 192 women found strong correlation of gestational age with TCD $(r=0.98)$, with BPD $(r=0.96)$ and with FL $(r=0.98)$ and recommends use of TCD routinely in estimating gestational age of the foetuses. ${ }^{7}$ Guan B measured fetal TCD in 335 women during 20 to 42 weeks of gestation and found curvilinear relationship between TCD and gestational age $(r=0.996 ; \mathrm{p}<$ $0.0005) .{ }^{8}$ Khemani $\mathrm{M}$ et al studied 235 women and found strong correlation of TCD with BPD $(\mathrm{R} 2=0.996$; $\mathrm{p}<$ $0.00001){ }^{9} \quad$ Mayer $\mathrm{W}$ et al investigated relationship between fetal TCD and AC throughout pregnancy in 700 well dated pregnancies between 14 to 42 weeks of gestation and found strong correlation between GA and TCD $(\mathrm{R} 2=0.9464)$ and between GA and AC (R2 = $0.9685) .{ }^{10}$ Malik et al 100 women in 16-40 weeks of pregnancy and found that TCD showed $92 \%$ predictive accuracy as compared to standard nomogram by Alman D G et al, Goel P et al studied 50 women in 14-40 weeks of pregnancy and found that TCD had good correlation with gestational age (correlation coefficient 0.991p less than 0.001). ${ }^{11-13}$ Naseem $F$ et al studied 228 patients in third trimester of pregnancy and found that TCD $(91.7 \%$, $\mathrm{p}=0.001$ ) was more correct to give assessment of gestational age than BPD in 176 patients $(77.2 \%){ }^{14}$ Bansal $M$ et al studied 650 cases between 14-40 weeks of gestation and found that TCD correlates with gestational age more than BPD. ${ }^{15}$ (Correlation coefficient-0.97305, $\mathrm{p}$ value-0.001). Adeyekun AA et al studied 450 women between 14-42 weeks of pregnancy and found that TCD had a higher predictive accuracy of $96.9 \% \pm 12$ days compared to BPD $(93.8 \% \pm 14.1$ days $)$ and $\mathrm{AC}$ $\left(92.7 \% \pm 15.3\right.$ days). ${ }^{16}$ TCD correlated more with significantly with menstrual age as compared to other biometric parameters $(r=0.984, p=0.000)$.

\section{CONCLUSION}

Normative cerebellar measurements throughout pregnancy permit estimation of gestational age independent of the shape of fetal head and also offer potential for evaluating abnormal fetal growth and anomalous development of central nervous system and TCD alone can also be the strong predictor of gestational age.

Funding: No funding sources

Conflict of interest: None declared

Ethical approval: The study was approved by the Institutional Ethics Committee

\section{REFERENCES}

1. Reddy UM, Abuhamad AZ, Levine D, Saade GR. Fetal imaging: executive summary of a joint Eunice Kennedy Shriver National Institute of child health and human development, society for maternal-fetal medicine, American Institute of Ultrasound in Medicine, American College of Obstetricians and Gynecologists, American College of Radiology, Society for Pediatric Radiology, and Society of Radiologists in Ultrasound Fetal Imaging workshop. Fetal Imaging Workshop Invited Participants. Obstet Gynecol. 2014;123:1070-82.

2. Butt K, Lim K. Determination of gestational age by ultrasound; SOGC clinical practice guide lines. J Obstet Gynaecol Can. 2014;36(2):171-81.

3. Goldstein I, Albert R, Pilu G, Hobbins JC. Cerebellar measurements with ultrasonography in the evaluation of fetal growth and development. Am J Obstet Gynecol. 1987;156:1065.

4. Micovic Z, Markovic A. growth of fetal cerebellum in normal pregnancy; Jugosol. Ginecol. Perinatol. (Yugoslavia). 1989;29:157.

5. Montenegro NA, Leite LP. Fetal cerebellar measyrementsin second trimester ultrasonography, clinical value; J Pernat Med. 1989;17:365.

6. Hata $\mathrm{K}$, Hata $\mathrm{T}$, Senoh $\mathrm{D}$, Makinara $\mathrm{K}$. Ultrasonographic measurement of fetal TCD in utero. Gynecol Obstet Invest. 1989;28:111.

7. Nikolov V, Khandzhier A, Brankova M. The echographic measurement of fetal transverse cerebellar diameter in the second pregnancy trimester: a nonstandard method for determining gestational age. Akuush Ginecol. 1991;30:16.

8. Guan B. Surveillance of fetal growth and fetal cerebellar transverse diameter by ultrasonographic measurement. Chung Hsueh Tsa Chih (Taipei) China. 1992;72:65.

9. Khemani M, Gupta A, Mittal KP, Sachdeo G. Ultrasonic evaluation of fetal cerebellar measurements as an independent marker for estimating gestational age in second and third trimester of pregnancy. J Obstet Gynecol Ind. $1993 ; 43: 497$. 
10. Mayer WJ, Gawthier DW, Goldberg B. Fetal TCD/AC ratio: a gestational age independent method of assessing fetal size. J Ultrasound Med. 1993; 12:379.

11. Malik R, Pandya VK, Shrivastav P. gestational age estimation using trans-cerebellar diameter with grading of fetal cerebellum and evaluation of TCD/AC ratio as a gestational age independent parameter. Indian J Radiol Imaging. 2003;13:95-7.

12. Altman DG, Chitty LS. Charts of fetal size methodology. Br J Obstetgynecol. 1994;101:29-34.

13. Goel P, Singla M, Ghai R. Trans-cerebellar diametera marker for estimation of gestational age. J Anat Soc India. 2010;59(2)158-61.
14. Naseem F, Fatima N. Comparision between transcerebellar diameter with biparietal diameter of ultrasound for gestational age measurement in third trimester of pregnancy. J Col Phys Surg Pakistan. 2013;23(5):322-5.

15. Bansal M, Bansal A. A study of correlation of transverse cerebellar diameter with gestational age in the normal and growth restricted foetuses in western Uttar Pradesh. Peop J Sci Res. 2014;7(2).

16. Adeyekun AA, Orji MO. Predictive accuracy of trans-cerebellar diameter in comparision with other fetal biometric parameters for gestational age estimation among pregnant Nigerian women. East Afr Med J. 2014;91(4):138-44.

Cite this article as: Uikey PA, Kedar KV, Khandale SN. Role of trans-cerebellar diameter in estimating gestational age in second and third trimester of pregnancy. Int J Reprod Contracept Obstet Gynecol 2016;5:3411-5. 